\title{
Hypertensive disorders of pregnancy and the recent increase in obstetric acute renal failure in Canada: population based retrospective cohort study
}

\author{
(c) (1) (8) OPEN ACCESS
}

\begin{abstract}
Azar Mehrabadi PhD candidate ${ }^{12}$, Shiliang Liu senior research scientist ${ }^{3}$, Sharon Bartholomew senior epidemiologist ${ }^{3}$, Jennifer A Hutcheon assistant professor ${ }^{12}$, Laura A Magee clinical professor $^{124}$, Michael S Kramer professor ${ }^{5}$, Robert M Liston professor emeritus ${ }^{1}, \mathrm{~K}$ S Joseph professor $^{12}$, for the Canadian Perinatal Surveillance System (Public Health Agency of Canada)

'Department of Obstetrics and Gynaecology, University of British Columbia and the Children's and Women's Health Centre of British Columbia, Vancouver, BC, Canada; ${ }^{2}$ School of Population and Public Health, University of British Columbia, Vancouver, BC, Canada; ${ }^{3}$ Maternal and Infant Health Section, Public Health Agency of Canada, Ottawa, ON, Canada; ${ }^{4}$ Division of General Internal Medicine, Faculty of Medicine, University of British Columbia, Vancouver, BC, Canada; ${ }^{5}$ Department of Pediatrics, and Department of Epidemiology, Biostatistics and Occupational Health, McGill University, Montreal, QC, Canada
\end{abstract}

\begin{abstract}
Objective To examine whether changes in postpartum haemorrhage, hypertensive disorders of pregnancy, or other risk factors explain the increase in obstetric acute renal failure in Canada.

Design Retrospective cohort study.

Setting Canada (excluding the province of Quebec).

Participants All hospital deliveries from 2003 to 2010 ( $n=2193$ 425).

Main outcome measures Obstetric acute renal failure identified by ICD-10 diagnostic codes
\end{abstract}

Methods Information on all hospital deliveries in Canada (excluding Quebec) between 2003 and 2010 ( $n=2193$ 425) was obtained from the Canadian Institute for Health Information. Temporal trends in obstetric acute renal failure were assessed among women with and without postpartum haemorrhage, hypertensive disorders of pregnancy, or other risk factors. Logistic regression was used to determine if changes in risk factors explained the temporal increase in obstetric acute renal failure.

Results Rates of obstetric acute renal failure rose from 1.66 to 2.68 per 10000 deliveries between 2003-04 and 2009-10 (61\% increase, 95\% confidence interval $24 \%$ to $110 \%$ ). Adjustment for postpartum haemorrhage, hypertensive disorders, and other factors did not attenuate the increase. The temporal increase in acute renal failure was restricted to deliveries with hypertensive disorders (adjusted increase 95\%, 95\% confidence interval $38 \%$ to $176 \%$ ), and was especially pronounced among women with gestational hypertension with significant proteinuria (adjusted increase 171\%, $71 \%$ to $329 \%$ ). No significant increase occurred among women without hypertensive disorders (adjusted increase $12 \%$, -28 to $72 \%$ )

Conclusions The increase in obstetric acute renal failure in Canada between 2003 and 2010 was restricted to women with hypertensive disorders and was especially pronounced among women with pre-eclampsia. Further study is required to determine the cause of the increase among women with pre-eclampsia.

\section{Introduction}

Obstetric acute renal failure, also referred to as pregnancy related acute kidney injury, is a serious and potentially life threatening complication of pregnancy. ${ }^{1-3}$ During the past 50 years, substantial declines in obstetric acute renal failure occurred in high income countries, owing to improvements in obstetric care and to the legalisation of pregnancy terminations and an associated decrease in infections. ${ }^{4-6}$ In recent years, however, rates have increased in both Canada and the United States. ${ }^{78}$ In Canada, obstetric acute renal failure increased significantly, from 1.6 per 10000 deliveries in 2003 to 2.3 per 10000 deliveries in $2007,{ }^{7}$ whereas the rate in the United States increased from 2.3 in 1998 to 4.5 per 10000 deliveries in $2008 .^{8}$ These increases are of concern because obstetric acute renal failure is associated with high rates of maternal morbidity and a case fatality rate of $2.9 \% .^{1}$ Major risk factors for obstetric acute renal failure include chronic hypertensive disease, 
pre-eclampsia, postpartum haemorrhage, antepartum haemorrhage, sepsis, and other infections. ${ }^{24910}$

Since rates of postpartum haemorrhage have increased in several high income countries, ${ }^{11-17}$ we hypothesised that the hypovolaemia and related organ failure associated with postpartum haemorrhage may have been responsible for the observed increase in obstetric acute renal failure. An alternative hypothesis was related to hypertensive disorders of pregnancy, which represents the most important risk factor for obstetric acute renal failure. ${ }^{49}$ Although the rate of hypertensive disorders of pregnancy has not changed substantially in recent years in Canada, ${ }^{18}$ there have been considerable changes in the management of hypertension in pregnancy. ${ }^{19}$ In particular, guidelines promoting fluid restriction to prevent pulmonary oedema or changes in drugs for control of hypertension in combination with changes in pain management may have had the secondary effect of increasing acute renal failure through hypovolaemia, renal hypoperfusion, or nephrotoxicity. ${ }^{19-22}$

We aimed to determine whether the temporal increase in postpartum haemorrhage in Canada explained the concurrent increase in obstetric acute renal failure. A secondary objective was to examine whether changes in hypertensive disorders of pregnancy (particularly pre-eclampsia) or other risk factors explained the increase in obstetric acute renal failure.

\section{Methods}

We obtained data from the discharge abstract database of the Canadian Institute for Health Information. This is a national database that contains information on all admissions to hospital in Canada (excluding Quebec) and includes personal details, medical history, diagnoses, and procedures associated with each hospital admission. The database has been validated and is routinely used for surveillance and research purposes. ${ }^{23}$ The study cohort included all hospital deliveries ( $n=2193425)$ in Canada (excluding the province of Quebec), that resulted in a live birth or stillbirth from April 2003 to March 2011 (hereafter referred to as 2003 to 2010).

Postpartum haemorrhage was defined using ICD-10CA (international statistical classification of diseases and related health problems (Canadian version,) codes O72.0 to O72.3, as a blood loss of $\geq 500 \mathrm{~mL}$ after vaginal delivery or $\geq 1000 \mathrm{~mL}$ after cesarean delivery, or as noted in the medical record by a care provider. Subtypes of postpartum haemorrhage were similarly identified using appropriate codes (see supplementary table 1). We defined severe postpartum haemorrhage as postpartum haemorrhage plus blood transfusion, hysterectomy, or other procedures to control bleeding. A validation study of the discharge abstract database reported a sensitivity of $90.2 \%$ and specificity of $98.2 \%$ for postpartum haemorrhage, and a sensitivity of $85.7 \%$ and specificity of $99.8 \%$ for blood transfusion. ${ }^{23}$

Hypertensive disorders of pregnancy included pre-existing hypertension with or without superimposed proteinuria (O10-O11), gestational hypertension without significant proteinuria (O13), gestational hypertension with significant proteinuria (O14), eclampsia (O15), and unspecified maternal hypertension (O16). The validation study of the discharge abstract database reported a sensitivity of $87.9 \%$ and a specificity of $99.6 \%$ for gestational hypertension and a sensitivity of $83.3 \%$ and a specificity of $99.9 \%$ for pre-existing hypertension. ${ }^{23}$

Acute renal failure among women admitted for childbirth was defined using standard ICD-10 codes, including those for postpartum acute renal failure (O90.4), post-procedural renal failure (N99.0), acute renal failure (N17), and unspecified kidney failure (N19). ${ }^{7810}$ The outcome of acute renal failure was based on the healthcare provider's documentation of this diagnosis in the woman's medical chart. To avoid potential temporal ambiguity between the determinant and the outcome (that is, acute renal failure preceding postpartum haemorrhage), we repeated our analyses after restricting the study to cases of postpartum acute renal failure (O90.4). To enhance the stability of rate estimates we estimated temporal trends in obstetric acute renal failure by year and also in two year periods. To ensure that any temporal changes did not merely reflect changes in the occurrence or reporting of milder cases, we examined rates of maternal death, dialysis, and intensive care unit admission among women with obstetric acute renal failure.

Other determinants of acute renal failure examined in the study were maternal age and parity, multi-fetal gestation, caesarean delivery, and induction of labour. Maternal comorbidity examined included diabetes (pre-existing or gestational), gestational oedema and proteinuria without hypertension, sepsis, other puerperal infection, placenta praevia, placental abruption, unspecified antepartum haemorrhage, uterine rupture, and cardiac failure.

We first assessed temporal trends in annual rates of obstetric acute renal failure, postpartum haemorrhage, hypertensive disorders, and other risk factors using the $\chi^{2}$ test for linear trend in proportions. Among cases of obstetric acute renal failure, the frequency of these risk factors was quantified in both the first half (2003-06) and the second half (2007-10) of the study period (the test for linear trend in proportions was based on the rate for each year of study). Rates of acute renal failure were also quantified among women with and without postpartum haemorrhage, with and without hypertensive disorders, and other risk factors.

Logistic regression analyses were carried out to quantify the effects of period (2009-10 $v$ 2003-04) on obstetric acute renal failure, while controlling for potential confounders; the contrast between 2009-10 and 2003-04 was intended to facilitate the interpretation of changes in rates over time. To determine whether the crude temporal increase was explained by changes in postpartum haemorrhage and other risk factors we compared the unadjusted and adjusted odds ratios expressing the temporal change in obstetric acute renal failure. We also modeled the temporal change in obstetric acute renal failure with calendar year of delivery (2003 to 2010) entered as a continuous variable in the logistic model.

We assessed the statistical significance of the interaction term between calendar year and gestational hypertension with proteinuria. This post hoc analysis was motivated by observed differences in temporal trends in obstetric acute renal failure among women with and women without gestational hypertension with proteinuria. We repeated analyses within strata of interest (for example, among women with and without postpartum haemorrhage, and among women with and without gestational hypertension with proteinuria). Sensitivity analyses explored whether temporal trends in obstetric acute renal failure were better explained by changes in severe postpartum haemorrhage (instead of any postpartum haemorrhage) or by modeling age as a continuous covariate using restricted cubic splines. ${ }^{24}{ }^{25} \mathrm{We}$ also carried out a post hoc assessment of temporal trends in rates of pulmonary oedema. Finally, we assessed if adjustment for other potential confounders-namely, previous caesarean delivery, chronic kidney disease, obesity, and obstetric shock-accounted for temporal changes in obstetric acute renal failure. 
All analyses were conducted using the statistical software package SAS version 9.3 and Stata SE version 11.

\section{Results}

Among the 2193425 hospital deliveries in Canada between 2003 and 2010, 502 cases of obstetric acute renal failure were observed; the rate increased by $61 \%(95 \%$ confidence interval $24 \%$ to $110 \%$ ) between 2003-04 and 2009-10, from 1.66 to 2.68 per 10000 deliveries (table $1 \Downarrow$ ). The increase in obstetric acute renal failure coincided with a $21 \%$ (95\% confidence interval $19 \%$ to $23 \%$ ) increase in postpartum haemorrhage (table 1). Hypertensive disorders of pregnancy increased slightly, from $6.0 \%$ of deliveries in 2003-04 to 6.3\% in 2009-10 (P for trend $<0.001$ ), whereas gestational hypertension with significant proteinuria remained at $1.1 \%$ throughout the study period $(\mathrm{P}$ for trend 0.44). The frequency of older maternal age in the cohort increased from $17.7 \%$ in 2003-04 to $19.2 \%$ in 2009-10. A small temporal decline was observed in nulliparity, while multi-fetal pregnancy and history of previous caesarean delivery increased over the same period. Table 1 summarises the maternal and obstetric characteristics (including rates of labour induction and caesarean delivery).

Table $2 \Downarrow$ summarises the characteristics of the women with acute renal failure in the first and second half of the study period. The proportion of acute renal failure cases with atonic postpartum haemorrhage increased significantly, from $12.3 \%$ in $2003-06$ to $19.3 \%$ in $2007-10$ ( $\mathrm{P}$ for trend=0.03, table 2). Similarly, the proportion of women with any hypertensive disorder increased significantly among cases; in particular, the proportion of women with gestational hypertension with proteinuria increased from $33.0 \%$ in $2003-06$ to $41.4 \%$ in 2007-10 (P for trend $<0.01$, table 2). Rates of maternal death, admission to an intensive care unit, and dialysis among cases of acute renal failure did not change significantly between the first and second half of the study period (table 2).

Rates of obstetric acute renal failure increased among women with and women without postpartum haemorrhage (table $3 \Downarrow$ ). Among women with postpartum haemorrhage, rates of acute renal failure increased by $79 \%$ (95\% confidence interval $5 \%$ to $206 \%$ ) from 2003-04 to 2009-10 (P for trend=0.06), whereas among women without postpartum haemorrhage, rates of acute renal failure increased by $47 \%$ (8\% to $100 \%$ ) between $2003-04$ and 2009-10 ( $\mathrm{P}$ for trend=0.005).

There was no significant increase in obstetric acute renal failure among women without hypertensive disorders ( $21 \%$ increase, $95 \%$ confidence interval $-21 \%$ to $86 \%$ ). Among women with hypertensive disorders, obstetric acute renal failure increased by $85 \%$ (32\% to $161 \%$ ) from 15.6 per 10000 deliveries in 2003-04 to 28.8 per 10000 in 2009-10 (table 3). The increase in obstetric acute renal failure among women with gestational hypertension with proteinuria was even more striking; rates of acute renal failure increased by $142 \%$ ( $55 \%$ to $281 \%$ ) from 45.5 per 10000 deliveries in 2003-04 to 109.6 per 10000 in 2009-10. Obstetric acute renal failure did not increase significantly among subtypes of hypertensive disorders other than gestational hypertension with significant proteinuria. Analyses restricted to women without hypertensive disorders of pregnancy showed no statistically significant increase in obstetric acute renal failure among women with or without postpartum haemorrhage (table 3). Calendar period modified the effect of gestational hypertension with proteinuria on obstetric acute renal failure (figure $\Downarrow$ ). The figure also shows that the effect of postpartum haemorrhage on obstetric acute renal failure was essentially unaffected by calendar period.
The crude temporal increase in obstetric acute renal failure between 2003-04 and 2009-10 (odds ratio $2.42,95 \%$ confidence interval 1.55 to 3.81 ) among women with gestational hypertension and significant proteinuria was not materially changed by adjustment for risk factors (adjusted odds ratio 2.71, $95 \%$ confidence interval 1.71 to 4.29 , table 3 ). Nor did adjustment for risk factors change the non-significant increase in obstetric acute renal failure among women without hypertensive disorders between 2003-04 and 2009-10 (adjusted odds ratio $1.12,0.72$ to 1.72 ).

Table $4 \Downarrow$ shows the results of crude and adjusted logistic regression models with and without an interaction term between gestational hypertension with proteinuria and year of delivery (year entered as a continuous variable). Several risk factors were strongly associated with obstetric acute renal failure, including pre-existing hypertension with proteinuria, gestational hypertension with significant proteinuria, non-atonic postpartum haemorrhage, gestational oedema with proteinuria, sepsis, and cardiac failure. The crude temporal increase in obstetric acute renal failure (odds ratio per year $1.08,95 \%$ confidence interval 1.04 to 1.12 ) was essentially unchanged after adjustment for potential confounders $(1.09,1.05$ to 1.14$)$. However, the interaction term between year of delivery and gestational hypertension with proteinuria was statistically significant $(\mathrm{P}<0.001)$; the temporal increase in rates of obstetric acute renal failure among women without gestational hypertension with proteinuria (odds ratio per year $1.03,0.98$ to 1.08 ) was significantly different from the temporal increase in rates of obstetric acute renal failure among women with gestational hypertension with proteinuria (odds ratio per year $1.03 \times 1.17=1.21$, table 4 ). Logistic regression analyses restricted to women with gestational hypertension and proteinuria and to women without hypertensive disorders of pregnancy showed essentially the same results (see supplementary tables 2 and 3 , respectively).

Table $5 \Downarrow$ shows temporal trends in rates of pulmonary oedema among all women and among women with and without hypertensive disorders. Rates declined among all women, although temporal trends were not statistically significant in any subgroup. Among women with gestational hypertension and proteinuria, pulmonary oedema rates declined substantially, from 77.0 per 10000 deliveries in 2003-04 to 63.9 per 10000 in 2005-06 and then increased to 74.1 per 10000 in 2009-10.

The overall increase in acute renal failure resulted in 58 excess cases of acute renal failure in 2009-10; 47 (81\%) of these excess cases occurred among women with hypertensive disorders of pregnancy and $42(72 \%)$ occurred among women with gestational hypertension with significant proteinuria, a subset of women with hypertensive disorders of pregnancy. Only nine excess cases of acute renal failure occurred in 2009-10 among women with postpartum haemorrhage without hypertensive disorders of pregnancy. Additional analyses revealed that temporal changes in postpartum acute renal failure were similar to temporal changes in overall obstetric acute renal failure. Study results were unchanged when severe postpartum haemorrhage was modeled as a determinant of obstetric acute renal failure instead of postpartum haemorrhage, when maternal age was modeled using restricted cubic splines, and when additional adjustment was made for previous cesarean delivery, chronic kidney disease, obstetric shock, and obesity.

\section{Discussion}

Rates of obstetric acute renal failure increased significantly in Canada between 2003 and 2010, from 1.66 per 10000 deliveries 
in 2003-04 to 2.68 per 10000 in 2009-10. Rates of admission to an intensive care unit, dialysis, and maternal death among cases of obstetric acute renal failure did not change significantly across this period, suggesting no change in the severity of the renal failure. Although rates of postpartum haemorrhage increased substantially over the same period and hypertensive disorders rose slightly, these rate changes did not explain the increase in rates of obstetric acute renal failure. The increase in obstetric acute renal failure was due to a change in rates of this complication in the small (approximately 6\%) subpopulation of women with hypertensive disorders of pregnancy, and it was particularly striking among the smaller subset of women with gestational hypertension and significant proteinuria.

\section{Strengths and limitations of this study}

Strengths of our study included its population based cohort design and large sample size, which allowed the study of rare outcomes. Furthermore, we were able to adjust for sepsis, diabetes mellitus, and other important risk factors for obstetric acute renal failure while examining the effects of postpartum haemorrhage and hypertensive disorders of pregnancy. Another strength was the demonstrated validity of our data source for postpartum haemorrhage and hypertensive disorders of pregnancy. ${ }^{23}$ Limitations of our study include inaccuracies in the data source, such as potential inaccurate diagnosis of obstetric acute renal failure, ${ }^{26}$ or changes in the clinical criteria for diagnosis over time. Although such inaccuracies are inherent in any large database, definitions of acute renal failure and postpartum haemorrhage in the ICD-10 Canadian version remained unchanged over the study period, and the codes for acute kidney injury have been extensively validated in the non-pregnant population. ${ }^{27-29}$ The rate of gestational hypertension with significant proteinuria (pre-eclampsia) in our study was lower than overall rates of pre-eclampsia reported elsewhere. ${ }^{30}$ Before 2012, the ICD-10 Canadian version included women with mild pre-eclampsia under the code for gestational hypertension without significant proteinuria. Therefore the code corresponding to "gestational hypertension with significant proteinuria" possibly included moderate to severe cases of pre-eclampsia only. Furthermore, gestational hypertension with proteinuria in our study did not include women with pre-existing hypertension and superimposed pre-eclampsia. Nevertheless, the rate of gestational hypertension with significant proteinuria was stable between 2003 and 2010, suggesting a constancy of coding practices during the study period. Information on prepregnancy body mass index and the severity of hypertensive disorders of pregnancy was not available in the database. While we included obesity (identified using ICD 10 Canadian version codes) in sensitivity analyses, this diagnosis is known to underestimate the true prevalence of obesity. ${ }^{31}$ Finally, further study is required to assess long term renal function among women with a diagnosis of obstetric acute renal failure. Although a few small studies suggest good renal outcomes among women with hypertension in pregnancy and obstetric acute renal failure, ${ }^{32} 33$ few high quality, long term studies have dealt with the long term prognosis of pregnancy related acute kidney injury. ${ }^{34}$

\section{Comparison with other studies}

The considerable increase in acute renal failure among women with gestational hypertension and significant proteinuria may be due to recent changes in the management of pre-eclampsia, such as changes in fluid management or antihypertensive treatment. Recent clinical practice guidelines have promoted the use of fluid restriction (to $80 \mathrm{~mL} /$ hour in the peripartum period, to prevent pulmonary oedema and other complications of fluid overload), magnesium sulphate use (for seizure prophylaxis), and antihypertensive pharmacotherapy (with preferred drugs such as nifedipine, labetalol, hydralazine, and methyldopa). ${ }^{1935}$ The management of hypertension in pregnancy, particularly in cases of pre-eclampsia, is complex. Competing priorities include lowering blood pressure and preventing maternal seizures, and preventing very preterm birth, intrauterine growth restriction, and other complications. Although the best available evidence suggests that the currently recommended management for pre-eclampsia is effective in reducing the frequency of eclampsia and other complications, ${ }^{19}$ an increase in a rare, unintended side effect such as acute renal failure cannot be ruled out. Previous studies have suggested that fluid restriction protocols in pre-eclampsia may have the secondary effect of increasing rates of acute renal failure through hypovolaemia and renal hypoperfusion. ${ }^{19}{ }^{20}$ On the other hand, fluid overload in pre-eclampsia treatment is associated with maternal deaths related to pulmonary oedema, ${ }^{36}$ and current guidelines emphasise the benefits of preventing pulmonary oedema and other consequences of fluid overload. ${ }^{20}$ In our study, we found no significant reduction in rates of pulmonary oedema among women with gestational hypertension with significant proteinuria (although the temporal pattern in rates was complex and non-linear). However, policies restricting fluids in the treatment of pre-eclampsia have been associated with significantly lower rates of pulmonary oedema in previous research. ${ }^{19}{ }^{37}$ It may therefore be prudent to continue fluid restriction protocols to prevent serious maternal complications, with more careful monitoring of renal function, until further studies provide clarity about the risks and benefits of such management.

Other changes in the management of pre-eclampsia that may have been responsible for the increase in acute renal failure include interactions among antihypertensive drugs and drugs used during pregnancy and immediately post partum. For instance, the recommended switch to non-steroidal anti-inflammatory drugs and paracetamol for postpartum pain in 2006, followed reports of codeine related toxicity in newborn infants through breast feeding. ${ }^{38}$ Non-steroidal anti-inflammatory drugs are a known risk factor for acute renal failure ${ }^{39}$ and have been implicated in obstetric acute renal failure. ${ }^{9}$ In a non-obstetric population, antihypertensive drugs in triple therapy combinations with non-steroidal anti-inflammatory drugs, also seem to increase the risk of acute kidney injury. ${ }^{40}$ In addition, higher dose (versus low dose) statin treatment is reported to be associated with acute kidney injury. ${ }^{41}$ However, owing to concerns about fetal safety, antihypertensive drugs used in pregnancy are different from standard pharmacotherapy. Suggested mechanisms for kidney injury due to antihypertensive drugs prescribed in pregnancy include prerenal azotaemia (due to decreased blood volume) with vasodilators such as hydralazine and calcium channel blockers, ureteral obstruction secondary to retroperintoneal fibrosis for methyldopa and hydralazine, hyperkaelaemia for $\beta$ blockers, and a "pseudonephrotoxicity" due to interference with laboratory determination of creatinine for methyldopa, without other clinical signs. ${ }^{42}$ A recent study reported that the antibiotic clarithromycin may interact with nifedipine to increase the risk of acute kidney injury through the inhibition of the CYP3A4 enzyme. ${ }^{43}$ Further study is required to determine whether antihypertensive drugs affect renal function in pregnancy and post partum.

Although postpartum haemorrhage did not explain the increase in obstetric acute renal failure, it was an important risk factor 
for acute renal failure, as reported in previous studies. ${ }^{3}{ }^{10}$ The absence of an increase in acute renal failure despite the increase in postpartum haemorrhage may have been due to appropriate and aggressive treatment of postpartum haemorrhage, which possibly prevented severe hypovolaemia related to blood loss. This is evidenced by increases in postpartum haemorrhage in conjunction with blood transfusion and surgical procedures to control bleeding, including arterial embolisation, uterine artery ligation, and the use of uterine compression sutures.

\section{Conclusions and clinical implications}

In conclusion, we observed a significant increase in obstetric acute renal failure in Canada that was restricted to women with hypertensive disorders of pregnancy and was particularly evident among those with gestational hypertension with significant proteinuria. Further studies are required to confirm our findings, including those related to temporal trends in pulmonary oedema, and to determine the specific aspect of pre-eclampsia management (fluid restriction, antihypertensive and other drug use) that may be increasing the risk of pregnancy related kidney injury. In addition, the long term impact of pregnancy related kidney injury requires further study. Meanwhile, clinicians managing women with pre-eclampsia should carefully monitor them for signs of impending renal failure and take appropriate steps to mitigate the risk of further kidney injury.

Contributors: AM and KSJ were responsible for the intellectual content of the study proposal; they developed and articulated the conceptual framework and the first draft of the study design. AM, KSJ, SL, and JAH developed the analytical approach. AM and SL analysed the data and AM wrote the first draft of the manuscript. SL, SB, JAH, LAM, MSK, $\mathrm{RML}$, and KSJ made contributions to the study design, analysis and interpretation of data and revised the article for important intellectual content. All authors read and approved the final manuscript. AM and KSJ are the guarantors for the study.

Funding: This work is supported by a Canadian Institutes of Health Research (CIHR) team grant in severe maternal morbidity

(MAH-115445). JAH is the recipient of a ClHR new investigator award and a scholar award from the Michael Smith Foundation for Health

Research. LAM receives salary support from British Columbia's Women's Hospital and Health Centre. KSJ is supported by an investigator award from the Child and Family Research Institute and a CIHR chair in maternal, fetal, and infant health services research (APR-126338). The funding sources had no role in the design, analysis, interpretation of the results, or the writing of the manuscript.

Competing interests: All authors have completed the ICMJE uniform disclosure form at www.icmje.org/coi disclosure.pdf and declare: no support from any organisation with competing interests for the submitted work; no financial relationships with any organisations that might have an interest in the submitted work in the previous three years; no other relationships or activities that could appear to have influenced the submitted work.

Ethical approval: The data source included denominalised information, and the Public Health Agency of Canada, which is mandated to monitor maternal and infant health in the Canadian population, is not required to obtain ethics review board approval for such studies.

Data sharing: No additional data available.

Transparency: AM affirms that the manuscript is an honest, accurate, and transparent account of the study being reported; that no important aspects of the study have been omitted; and that any discrepancies from the study as planned have been explained.

Joseph KS, Liu S, Rouleau J, Kirby RS, Kramer MS, Sauve R, et al. Severe maternal morbidity in Canada, 2003 to 2007: surveillance using routine hospitalization data and ICD-10CA codes. J Obstet Gynaecol Can 2010;32:837-46.
2 Nzerue CM, Hewan-Lowe K, Nwawka C. Acute renal failure in pregnancy: a review of clinical outcomes at an inner-city hospital from 1986-1996. J Natl Med Assoc 1998:90:486-90.

3 Acharya A, Santos J, Linde B, Anis K. Acute kidney injury in pregnancy-current status. Advn Chronic Kidney Dis 2013;20:215-22.

4 Turney JH, Ellis CM, Parsons FM. Obstetric acute renal failure 1956-1987. Br J Obstet Gynaecol 1989;96:679-87.

5 Krane NK. Acute renal failure in pregnancy. Arch Intern Med 1988;148:2347-57.

6 Stewart GK, Goldstein PJ. Therapeutic abortion in California. Effects of septic abortion and maternal mortality. Obstet Gynecol 1971;37:510-4.

7 Liu S, Joseph KS, Bartholomew S, Fahey J, Lee L, Allen AC, et al. Temporal trends and regional variations in severe maternal morbidity in Canada, 2003 to 2007. J Obstet Gynaecol Can 2010;32:847-55.

8 Callaghan WM, Creanga AA, Kuklina EV. Severe maternal morbidity among delivery and postpartum hospitalizations in the United States. Obstet Gynecol 2012;120:1029-36.

9 Gurrieri C, Garovic VD, Gullo A, Bojanic K, Sprung J, Narr BJ, et al. Kidney injury during pregnancy: associated comorbid conditions and outcomes. Arch Gynecol Obstet 2012;286:567-73.

10 Bateman BT, Berman MF, Riley LE, Leffert LR. The epidemiology of postpartum hemorrhage in a large, nationwide sample of deliveries. Anesth Analg 2010;110:1368-73.

11 Knight M, Callaghan WM, Berg C, Alexander S, Bouvier-Colle MH, Ford JB, et al. Trends in postpartum hemorrhage in high resource countries: a review and recommendations from the International Postpartum Hemorrhage Collaborative Group. BMC Pregnancy Childbirth 2009;9:55.

12 Joseph KS, Rouleau J, Kramer MS, Young DC, Liston RM, Baskett TF. Investigation of an increase in postpartum haemorrhage in Canada. BrJ Obstet Gynaecol2007;114:751-9,

13 Callaghan WM, Kuklina EV, Berg CJ. Trends in postpartum hemorrhage: United States, 1994-2006. Am J Obstet Gynecol 2010;202:353.e1-6.

14 Rossen J, Økland I, Bjarte Nilsen O, Eggebø TM. Is There an increase of postpartum hemorrhage, and is severe hemorrhage associated with more frequent use of obstetric interventions? Obstet Gynecol Surv 2011;66:18-20.

15 Lutomski JE, Byrne BM, Devane D, Greene RA. Increasing trends in atonic postpartum haemorrhage in Ireland: an 11-year population-based cohort study. Br J Obstet Gynaecol 2012;119:306-14

16 Ford JB, Roberts CL, Simpson JM, Vaughan J, Cameron CA. Increased postpartum hemorrhage rates in Australia. Int J Gynecol Obstet 2007;98:237-43.

17 Blomberg M. Maternal obesity and risk of postpartum hemorrhage. Obstet Gynecol 2011;118:561-8.

18 Mehrabadi A, Liu S, Bartholomew S, Hutcheon J, Kramer M, Liston R, et al. Temporal trends in postpartum hemorrhage in Canada from 2003 to 2009. J Obstet Gynaecol Can 2014;36:21-33.

19 Von Dadelszen P, Sawchuck D, McMaster R, Douglas MJ, Lee SK, Saunders S, et al. The active implementation of pregnancy hypertension guidelines in British Columbia. Obstet Gynecol 2010;116:659-66.

20 Tuffnell DJ, Jankowicz D, Lindow SW, Lyons G, Mason GC, Russell IF, et al. Outcomes of severe pre-eclampsia/eclampsia in Yorkshire 1999/2003. Br J Obstet Gynaecol 2005; $112: 875-80$.

21 Thadhani R, Pascual M, Bonventre JV. Acute renal failure. New Engl J Med 1996;334:1448-60

22 Magee LA, Helewa M, Moutquin JM, von Dadelszen P. Diagnosis, evaluation, and management of the hypertensive disorders of pregnancy. J Obstet Gynaecol Can 2008:30:S1-48.

23 Joseph KS, Fahey J. Validation of perinatal data in the Discharge Abstract Database of the Canadian Institute for Health Information. Chronic Dis Can 2009;29:96-100.

24 Harrell FE. Regression modeling strategies: with applications to linear models, logistic regression, and survival analysis. Springer-Verlag, 2001.

25 Howe CJ, Cole SR, Westreich DJ, Greenland S, Napravnik S, Eron JJ Jr. Splines for trend analysis and continuous confounder control. Epidemiology 2011;22:874-5.

26 Gammill HS, Jeyabalan A. Acute renal failure in pregnancy. Crit Care Med 2005;33:S372-84.

27 So L, Evans D, Quan H. ICD-10 coding algorithms for defining comorbidities of acute myocardial infarction. BMC Health Serv Res 2006;6:161.

28 Waikar SS, Wald R, Chertow GM, Curhan GC, Winkelmayer WC, Liangos O, et al. Validity of International Classification of Diseases, Ninth Revision, Clinical Modification Codes for Acute Renal Failure. J Am Soc Nephrol 2006;17:1688-94.

29 Hwang YJ, Shariff SZ, Gandhi S, Wald R, Clark E, Fleet JL, et al. Validity of the International Classification of Diseases, Tenth Revision code for acute kidney injury in elderly patients at presentation to the emergency department and at hospital admission. BMJ Open 2012;2:e001821.

30 Roberts CL, Ford JB, Algert CS, Antonsen S, Chalmers J, Cnattingius S, et al. Population-based trends in pregnancy hypertension and pre-eclampsia: an international comparative study. BMJ Open 2011;1:e000101.

31 Mehrabadi A, Hutcheon JA, Lee L, Kramer MS, Liston RM, Joseph KS. Epidemiologic investigation of a temporal increase in atonic postpartum hemorrhage: a population-based retrospective cohort study. Br J Obstet Gynaecol 2013:120:853-62.

32 Sibai BM, Villar MA, Mabie BC. Acute renal failure in hypertensive disorders of pregnancy. Pregnancy outcome and remote prognosis in thirty-one consecutive cases. Am J Obstet Gynecol 1990;162:777-83.

33 Drakeley AJ, Le Roux PA, Anthony J, Penny J. Acute renal failure complicating severe preeclampsia requiring admission to an obstetric intensive care unit. Am J Obstet Gynecol 2002;186:253-6.

34 Vikse BE. Pre-eclampsia and the risk of kidney disease. Lancet 2013;382:104-6.

35 Royal College of Obstetricians and Gynaelcologists. Management of severe pre-eclampsia/eclampsia. Guideline No 10(A). 2006.

36 Lewis G, ed. Why mothers die 2000-2002. The sixth report of the confidential enquiries into maternal deaths in the United Kingdom. RCOG Press, 2004.

37 Thornton CE, von Dadelszen P, Makris A, Tooher JM, Ogle RF, Hennessy A. Acute pulmonary oedema as a complication of hypertension during pregnancy. Hypertens Pregnancy 2011;30:169-79.

38 Koren G, Cairns J, Chitayat D, Gaedigk A, Leeder SJ. Pharmacogenetics of morphine poisoning in a breastfed neonate of a codeine-prescribed mother. Lancet 2006;368:704.

39 Abuelo JG. Normotensive ischemic acute renal failure. New Engl J Med 2007;357:797-805.

40 Lapi F, Azoulay L, Yin H, Nessim SJ, Suissa S. Concurrent use of diuretics, angiotensin converting enzyme inhibitors, and angiotensin receptor blockers with non-steroidal 


\section{What is already known on this topic}

Obstetric acute renal failure has increased in both Canada and the United States since early 2000, concurrent with an increase in postpartum haemorrhage

It is unclear whether postpartum haemorrhage, hypertensive disorders of pregnancy, or another risk factor underlies the increase in obstetric acute renal failure

\section{What this study adds}

This study showed that the increase in obstetric acute renal failure in Canada in 2003-10 was restricted to the 6\% of women with hypertensive disorders of pregnancy, and especially pronounced among women with pre-eclampsia

The increase in obstetric acute renal failure in Canada was not explained by the concurrent increase in postpartum haemorrhage Further study is required to determine the specific aspect of pre-eclampsia management that may have been responsible for the increase in obstetric acute renal failure

anti-inflammatory drugs and risk of acute kidney injury: nested case-control study. BMJ 2013;346:e8525

41 Dormuth CR, Hemmelgarn BR, Paterson JM, James MT, Teare GF, Raymond CB, et al. Use of high potency statins and rates of admission for acute kidney injury: multicenter, 42. Nephrol 2006;2:80-91.

43 Gandhi S, Fleet JL, Bailey DG, McArthur E, Wald R, Rehman F, et al. Calcium-channel blocker—clarithromycin drug interactions and acute kidney injury. JAMA 2013;310:2544-53.
Accepted: 15 July 2014

\section{Cite this as: BMJ 2014;349:94731}

This is an Open Access article distributed in accordance with the Creative Commons Attribution Non Commercial (CC BY-NC 3.0) license, which permits others to distribute, remix, adapt, build upon this work non-commercially, and license their derivative works on different terms, provided the original work is properly cited and the use is non-commercial. See: http://creativecommons.org/licenses/by-nc/3.0/. 


\section{Tables}

Table 1| Temporal trends in obstetric acute renal failure and in postpartum haemorrhage, hypertensive disorders of pregnancy, and other risk factors for obstetric acute renal failure, Canada (excluding Quebec), 2003-10 ( $n=2193$ 425)

\begin{tabular}{|c|c|c|c|c|c|c|}
\hline \multirow[b]{2}{*}{ Outcome/risk factor } & \multirow[b]{2}{*}{ No of cases 2003-10 } & \multicolumn{4}{|c|}{ Years } & \multirow[b]{2}{*}{$P$ for trend } \\
\hline & & 2003-04 & 2005-06 & 2007-08 & $2009-10$ & \\
\hline Acute renal failure per 10000 deliveries & 502 & 1.66 & 2.35 & 2.40 & 2.68 & $<0.001$ \\
\hline \multicolumn{7}{|l|}{ Risk factors per 100 deliveries } \\
\hline Postpartum haemorrhage: & 122676 & 5.06 & 5.18 & 5.92 & 6.13 & $<0.001$ \\
\hline Atonic & 97920 & 3.90 & 4.14 & 4.78 & 4.96 & $<0.001$ \\
\hline Non-atonic & 24756 & 1.16 & 1.04 & 1.15 & 1.16 & 0.08 \\
\hline \multicolumn{7}{|l|}{ Severe postpartum haemorrhage: } \\
\hline With blood transfusion & 9575 & 0.37 & 0.40 & 0.47 & 0.49 & $<0.001$ \\
\hline With hysterectomy & 1150 & 0.05 & 0.05 & 0.06 & 0.06 & $<0.01$ \\
\hline With other procedures & 1714 & 0.05 & 0.07 & 0.09 & 0.11 & $<0.001$ \\
\hline Any hypertensive disorder: & 134490 & 6.03 & 6.09 & 6.13 & 6.26 & $<0.001$ \\
\hline Pre-existing hypertension & 9695 & 0.41 & 0.44 & 0.45 & 0.46 & $<0.001$ \\
\hline Pre-existing hypertension with proteinuria & 2543 & 0.11 & 0.11 & 0.12 & 0.13 & 0.001 \\
\hline Gestational hypertension no proteinuria & 92528 & 4.10 & 4.19 & 4.22 & 4.35 & $<0.001$ \\
\hline Gestational hypertension with proteinuria & 24851 & 1.12 & 1.13 & 1.15 & 1.14 & 0.44 \\
\hline Unspecified hypertension & 4268 & 0.25 & 0.19 & 0.17 & 0.17 & $<0.001$ \\
\hline Eclampsia & 1684 & 0.12 & 0.08 & 0.06 & 0.06 & $<0.001$ \\
\hline \multicolumn{7}{|l|}{ Other risk factors per 100 deliveries } \\
\hline Maternal age $\geq 35$ years & 404529 & 17.7 & 18.2 & 18.6 & 19.2 & $<0.001$ \\
\hline Nulliparous $\dagger$ & 763115 & 45.1 & 44.6 & 44.3 & 44.4 & $<0.001$ \\
\hline Multi-fetal gestation & 30608 & 1.27 & 1.33 & 1.42 & 1.55 & $<0.001$ \\
\hline Previous caesarean & 281862 & 11.8 & 12.6 & 13.3 & 13.6 & $<0.001$ \\
\hline Diabetes & 112951 & 4.37 & 4.87 & 5.28 & 5.98 & $<0.001$ \\
\hline Gestational oedema and proteinuria & 2454 & 0.11 & 0.07 & 0.12 & 0.14 & $<0.001$ \\
\hline Sepsis & 2557 & 0.16 & 0.12 & 0.10 & 0.09 & $<0.001$ \\
\hline Other puerperal infection & 8615 & 0.48 & 0.41 & 0.35 & 0.33 & $<0.001$ \\
\hline Antepartum haemorrhage or placenta praevia & 20712 & 0.91 & 0.94 & 0.94 & 0.98 & $<0.001$ \\
\hline Placental abruption & 25783 & 1.24 & 1.15 & 1.15 & 1.17 & $<0.001$ \\
\hline Polyhydramnios & 10939 & 0.45 & 0.45 & 0.51 & 0.58 & $<0.001$ \\
\hline Induction of labour & 471515 & 21.0 & 20.4 & 20.1 & 24.4 & $<0.001$ \\
\hline Caesarean delivery & 600128 & 26.3 & 27.3 & 27.9 & 27.9 & $<0.001$ \\
\hline Uterine rupture & 2153 & 0.11 & 0.10 & 0.09 & 0.09 & $<0.01$ \\
\hline Obstetric shock & 544 & 0.02 & 0.02 & 0.03 & 0.03 & 0.04 \\
\hline Cardiac failure & 1837 & 0.08 & 0.09 & 0.08 & 0.10 & $<0.001$ \\
\hline Amniotic fluid embolism & 136 & 0.01 & 0.01 & 0.01 & 0.01 & 0.33 \\
\hline Chronic kidney disease & 172 & 0.01 & 0.01 & 0.01 & 0.01 & 0.75 \\
\hline
\end{tabular}

${ }^{*}$ Test for linear trend in proportions based on each year between 2003 and 2010.

†Proportion calculated excludes women with missing information for parity (22\% of deliveries). 
Table 2| Proportion of obstetric acute renal failure cases $(n=502)$ with postpartum haemorrhage, hypertensive disorders, other risk factors, and mortality or morbidity, Canada (excluding Quebec), 2003-06 and 2007-10

\begin{tabular}{|c|c|c|c|c|}
\hline \multirow[b]{2}{*}{ Risk factor/mortality or morbidity } & \multirow[b]{2}{*}{ No of cases 2003-10 } & \multicolumn{2}{|c|}{$\%$} & \multirow[b]{2}{*}{$P$ for trend } \\
\hline & & $2003-06(n=212)$ & $2007-10(n=290)$ & \\
\hline Postpartum haemorrhage: & 148 & 26.9 & 31.4 & 0.34 \\
\hline Atonic & 82 & 12.3 & 19.3 & 0.03 \\
\hline Non-atonic & 66 & 14.6 & 12.1 & 0.27 \\
\hline \multicolumn{5}{|l|}{ Non-atonic $†$} \\
\hline Due to retained placenta & 19 & 3.8 & 3.8 & 0.85 \\
\hline Secondary & 9 & 2.4 & 1.4 & 0.37 \\
\hline Due to coagulation defects & 55 & 12.3 & 10.0 & 0.31 \\
\hline \multicolumn{5}{|l|}{ Severe postpartum haemorrhage } \\
\hline Postpartum haemorrhage+blood transfusion & 93 & 17.5 & 19.3 & 0.64 \\
\hline Postpartum haemorrhage+hysterectomy & 25 & 3.3 & 6.2 & 0.22 \\
\hline Postpartum haemorrhage+other procedures & 15 & 1.9 & 3.8 & 0.23 \\
\hline Any hypertensive disorder: & 316 & 59.0 & 65.9 & 0.05 \\
\hline Pre-existing hypertension & 11 & 1.9 & 2.4 & 0.57 \\
\hline Pre-existing hypertension with proteinuria & 33 & 6.1 & 6.9 & 0.76 \\
\hline Gestational hypertension without proteinuria & 70 & 15.6 & 12.7 & 0.21 \\
\hline Gestational hypertension with proteinuria & 190 & 33.0 & 41.4 & $<0.01$ \\
\hline Unspecified hypertension & 11 & 3.3 & 1.4 & 0.08 \\
\hline Eclampsia & 16 & 2.8 & 3.5 & 0.66 \\
\hline Maternal age $\geq 35$ years & 143 & 23.6 & 32.1 & 0.07 \\
\hline Nulliparous $¥$ & 257 & 68.2 & 62.6 & 0.23 \\
\hline Multi-fetal gestation & 50 & 10.4 & 9.7 & 0.66 \\
\hline Previous caesarean & 52 & 9.0 & 11.4 & 0.27 \\
\hline Diabetes & 77 & 15.6 & 15.2 & 0.58 \\
\hline Gestational oedema and proteinuria & 8 & 1.9 & 1.4 & 0.98 \\
\hline Sepsis or other puerperal infection & 60 & 11.3 & 12.4 & 0.93 \\
\hline Antepartum haemorrhage/placenta praevia & 22 & 4.3 & 4.5 & 0.83 \\
\hline Placental abruption & 56 & 11.3 & 11.0 & 0.67 \\
\hline Polyhydramnios & 12 & 2.4 & 2.4 & 0.88 \\
\hline Induction of labour & 158 & 27.8 & 34.1 & 0.30 \\
\hline Caesarean delivery & 335 & 70.8 & 63.8 & 0.38 \\
\hline Uterine rupture & 5 & 0.9 & 1.0 & 0.69 \\
\hline Obstetric shock & 25 & 3.3 & 6.2 & 0.19 \\
\hline Cardiac failure & 35 & 6.6 & 7.2 & 0.29 \\
\hline Amniotic fluid embolism & 6 & 1.4 & 1.0 & 0.46 \\
\hline Chronic kidney disease & 13 & 2.8 & 2.4 & 0.60 \\
\hline Maternal death & 14 & 3.3 & 2.4 & 0.81 \\
\hline Intensive care unit admission & 191 & 41.0 & 35.9 & 0.24 \\
\hline Dialysis & 44 & 10.4 & 7.6 & 0.21 \\
\hline
\end{tabular}

${ }^{*}$ Test for linear trend in proportions based on each year between 2003 and 2010.

†Subcategories include women with more than one subtype of non-atonic postpartum haemorrhage.

†Proportion calculated excludes women with missing information for parity (22\% of deliveries). 
Table 3| Temporal trends in obstetric acute renal failure among women with and without postpartum haemorrhage and women with and without hypertensive disorders of pregnancy, Canada (excluding Quebec), 2003-10

\begin{tabular}{|c|c|c|c|c|c|c|c|c|c|}
\hline \multirow[b]{2}{*}{ Condition } & \multirow[b]{2}{*}{$\begin{array}{l}\text { No cases } \\
\text { in 2003-10 }\end{array}$} & \multicolumn{4}{|c|}{ Acute renal failure: rate per 10000 deliveries } & \multirow{2}{*}{$\begin{array}{l}\text { Odds ratio (95\% } \\
\text { CI): 2009-10 } v \\
2003-04\end{array}$} & \multirow[b]{2}{*}{$\begin{array}{l}P \text { for } \\
\text { trend* }\end{array}$} & \multirow{2}{*}{$\begin{array}{c}\text { Adjusted odds } \\
\text { ratio† }(95 \% \mathrm{Cl}): \\
2009-10 v \\
2003-04\end{array}$} & \multirow[b]{2}{*}{$\begin{array}{l}\text { Adjusted } P \\
\text { for trend‡ }\end{array}$} \\
\hline & & 2003-04 & 2005-06 & 2007-08 & $2009-10$ & & & & \\
\hline $\begin{array}{l}\text { Postpartum haemorrhage } \\
(\mathrm{n}=122676)\end{array}$ & 148 & 7.34 & 13.6 & 13.29 & 13.2 & $\begin{array}{l}1.79(1.05 \text { to } \\
3.06)\end{array}$ & 0.06 & $1.73(1.00$ to 3.00$)$ & 0.10 \\
\hline $\begin{array}{l}\text { No postpartum } \\
\text { haemorrhage }(n=2070 \\
749)\end{array}$ & 354 & 1.36 & 1.74 & 1.71 & 2.00 & $\begin{array}{c}1.47(1.08 \text { to } \\
2.00)\end{array}$ & 0.005 & $1.39(1.02$ to 1.90$)$ & 0.01 \\
\hline $\begin{array}{l}\text { Postpartum haemorrhage, } \\
\text { excluding hypertensive } \\
\text { disorders of pregnancy } \\
(n=112004)\end{array}$ & 69 & 3.4 & 8.2 & 6.5 & 6.3 & $\begin{array}{c}1.86(0.82 \text { to } \\
4.22)\end{array}$ & 0.39 & 1.84 (0.77 to 4.38$)$ & 0.55 \\
\hline $\begin{array}{l}\text { No postpartum } \\
\text { haemorrhage, excluding } \\
\text { hypertensive disorders of } \\
\text { pregnancy }(n=1946931)\end{array}$ & 117 & 0.64 & 0.60 & 0.57 & 0.60 & $\begin{array}{c}0.94(0.53 \text { to } \\
1.56)\end{array}$ & 0.98 & $0.89(0.53$ to 1.50$)$ & 0.85 \\
\hline $\begin{array}{l}\text { Hypertensive disorders } \\
(n=134490)\end{array}$ & 316 & 15.6 & 23.4 & 25.1 & 28.8 & $\begin{array}{c}1.85(1.32 \text { to } \\
2.61)\end{array}$ & $<0.001$ & 1.95 (1.38 to 2.76 ) & $<0.001$ \\
\hline $\begin{array}{l}\text { No hypertensive disorders } \\
(\mathrm{n}=2058935)\end{array}$ & 186 & 0.77 & 0.99 & 0.91 & 0.93 & $\begin{array}{c}1.21(0.79 \text { to } \\
1.86)\end{array}$ & 0.39 & $1.12(0.72$ to 1.72$)$ & 0.71 \\
\hline $\begin{array}{l}\text { Gestational hypertension } \\
\text { with significant proteinuria } \\
(\mathrm{n}=24851)\end{array}$ & 190 & 45.5 & 72.1 & 74.3 & 109.6 & $\begin{array}{c}2.42(1.55 \text { to } \\
3.81)\end{array}$ & $<0.001$ & 2.71 (1.71 to 4.29$)$ & $<0.001$ \\
\hline $\begin{array}{l}\text { No gestational } \\
\text { hypertension with } \\
\text { significant proteinuria }(n=2 \\
168574)\end{array}$ & 312 & 1.17 & 1.55 & 1.56 & 1.45 & $\begin{array}{c}1.25(0.89 \text { to } \\
1.74)\end{array}$ & 0.17 & 1.14 (0.81 to 1.60$)$ & 0.43 \\
\hline
\end{tabular}

*Test for linear trend in proportions based on each year between 2003 and 2010.

†Adjusted for maternal age, parity, multi-fetal gestation, diabetes, sepsis, other puerperal infection, antepartum haemorrhage or placenta praevia, placental abruption, polyhydramnios, induction of labour, caesarean delivery, uterine rupture, cardiac failure, and for years 2007-08 and 2006-05 versus 2003-04. Models including women with and without hypertensive disorders and with and without gestational hypertension with significant proteinuria were additionally adjusted for atonic postpartum haemorrhage and non-atonic postpartum haemorrhage.

¥Year of delivery modeled based on each year between 2003 and 2010. All other covariates adjusted for as above. 
Table 4 | Results of logistic regression modeling showing effects of year and risk factors on acute renal failure (ARF) among all deliveries ( $n=2193$ 425), Canada (excluding Quebec), 2003-10

\begin{tabular}{|c|c|c|c|c|}
\hline \multirow[b]{2}{*}{ Risk factors } & \multirow{2}{*}{$\begin{array}{l}\text { Rate of ARF per } \\
10000 \text { deliveries }\end{array}$} & \multicolumn{3}{|c|}{ Odds ratio $(95 \% \mathrm{Cl})$} \\
\hline & & Unadjusted & Model 1 without interaction term & Model 2 with interaction term* \\
\hline $\begin{array}{l}\text { Gestational hypertension with } \\
\text { proteinuria } \times \text { year of delivery } \\
\text { (interaction) }\end{array}$ & - & - & - & $1.17(1.08$ to 1.28$)$ \\
\hline Year of delivery & - & 1.08 (1.04 to 1.12$)$ & 1.09 (1.05 to 1.14$)$ & $1.03(0.98$ to 1.08$)$ \\
\hline Atonic postpartum haemorrhage & 8.37 & 4.18 (3.30 to 5.30$)$ & 3.56 (2.76 to 4.58$)$ & 3.55 (2.75 to 4.57$)$ \\
\hline Non-atonic postpartum haemorrhage & 26.7 & 13.3 (10.3 to 17.2$)$ & 12.5 (9.35 to 16.8$)$ & 12.5 (9.31 to 16.7$)$ \\
\hline \multicolumn{5}{|l|}{ Hypertensive disorders: } \\
\hline Pre-existing hypertension & 11.3 & $5.05(2.78$ to 9.18$)$ & 3.14 (1.67 to 5.89$)$ & 3.27 (1.75 to 6.13$)$ \\
\hline $\begin{array}{l}\text { Pre-existing hypertension with } \\
\text { proteinuria }\end{array}$ & 129.8 & 61.4 (43.0 to 87.6$)$ & 29.3 (19.7 to 43.7) & 29.9 (20.1 to 44.6$)$ \\
\hline $\begin{array}{l}\text { Gestational hypertension no } \\
\text { proteinuria }\end{array}$ & 7.57 & 3.68 (2.86 to 4.74$)$ & 4.68 (3.56 to 6.17$)$ & 4.71 (3.58 to 6.21$)$ \\
\hline $\begin{array}{l}\text { Gestational hypertension with } \\
\text { proteinuria }\end{array}$ & 76.5 & 53.6 (44.7 to 64.2$)$ & 31.6 (25.6 to 38.9$)$ & 14.1 (8.72 to 22.8$)$ \\
\hline Eclampsia & 95 & $43.3(26.2$ to 71.3$)$ & $8.29(4.70$ to 14.6$)$ & $8.32(4.70$ to 14.7$)$ \\
\hline Unspecified hypertension & 25.8 & 11.5 (6.3 to 21.0$)$ & $9.54(5.04$ to 18.1$)$ & $9.86(5.22$ to 18.7$)$ \\
\hline \multicolumn{5}{|l|}{ Maternal age (years): } \\
\hline$<20$ & 1.65 & 1.05 (0.61 to 1.80$)$ & 0.89 (0.51 to 1.54$)$ & $0.89(0.51$ to 1.54$)$ \\
\hline $20-24$ & 1.57 & Reference & Reference & Reference \\
\hline $25-29$ & 2.09 & 1.33 (0.97 to 1.82$)$ & $1.22(0.89$ to 1.68$)$ & $1.22(0.89$ to 1.68$)$ \\
\hline $30-34$ & 2.2 & 1.40 (1.03 to 1.90$)$ & $1.20(0.88$ to 1.65$)$ & $1.21(0.88$ to 1.65$)$ \\
\hline $35-39$ & 3.36 & 2.14 (1.55 to 2.94$)$ & 1.48 (1.06 to 2.07$)$ & 1.50 (1.07 to 2.09$)$ \\
\hline$\geq 40$ & 4.39 & 2.79 (1.79 to 4.34$)$ & $1.19(0.74$ to 1.90$)$ & $1.21(0.75$ to 1.93$)$ \\
\hline Parity 1: & 1.46 & Reference & Reference & Reference \\
\hline Nulliparous & 3.34 & 2.23 (1.76 to 2.83 ) & $1.46(1.14$ to 1.88$)$ & $1.46(1.13$ to 1.87$)$ \\
\hline $2-4$ & 1.53 & 1.01 (0.71 to 1.44$)$ & $1.03(0.72$ to 1.47$)$ & $1.02(0.71$ to 1.46$)$ \\
\hline$>5$ & 3.67 & 2.43 (1.23 to 4.83$)$ & 2.06 (1.02 to 4.15$)$ & 2.07 (1.03 to 4.16$)$ \\
\hline Missing & 1.99 & $1.32(0.99$ to 1.76$)$ & $0.87(0.64$ to 1.16$)$ & $0.86(0.64$ to 1.16$)$ \\
\hline Multi-fetal gestation & 16.3 & 7.83 (5.84 to 10.5$)$ & 2.12 (1.55 to 2.91$)$ & 2.10 (1.53 to 2.88$)$ \\
\hline Diabetes & 6.82 & 3.34 (2.62 to 4.26$)$ & 1.75 (1.35 to 2.26$)$ & 1.73 (1.34 to 2.25$)$ \\
\hline Gestational oedema and proteinuria & 32.6 & 14.5 (7.21 to 29.2$)$ & $8.40(4.02$ to 17.6$)$ & $8.39(4.02$ to 17.6$)$ \\
\hline Sepsis & 101.7 & $47.3(31.8$ to 70.3$)$ & $8.82(5.52$ to 14.1$)$ & 9.01 (5.64 to 14.4$)$ \\
\hline Other puerperal infection & 46.4 & 22.1 (16.0 to 30.5$)$ & 4.77 (3.28 to 6.93 ) & 4.84 (3.33 to 7.03 ) \\
\hline $\begin{array}{l}\text { Antepartum haemorrhage or } \\
\text { placenta praevia }\end{array}$ & 10.6 & 4.81 (3.14 to 7.38$)$ & $1.90(1.21$ to 3.01$)$ & 1.88 (1.19 to 2.98$)$ \\
\hline Placental abruption & 21.7 & $10.6(8.01$ to 14.0$)$ & 5.29 (3.93 to 7.11$)$ & 5.26 (3.91 to 7.07$)$ \\
\hline Polyhydramnios & 11.0 & 4.89 (2.76 to 8.67$)$ & 2.34 (1.27 to 4.31$)$ & 2.39 (1.30 to 4.41$)$ \\
\hline Induction of labour & 3.35 & 1.68 (1.39 to 2.03$)$ & $0.92(0.75$ to 1.13$)$ & $0.92(0.75$ to 1.13$)$ \\
\hline Caesarean delivery & 5.58 & 5.33 (4.43 to 4.81$)$ & 2.79 (2.25 to 3.44$)$ & 2.79 (2.25 to 3.44$)$ \\
\hline Uterine rupture & 23.2 & 10.3 (4.25 to 24.8$)$ & 3.14 (1.16 to 8.47$)$ & 3.13 (1.15 to 8.49$)$ \\
\hline Cardiac failure & 190.5 & 91.1 (64.4 to 128.9$)$ & $11.0(7.38$ to 16.4$)$ & $11.3(7.55$ to 16.8$)$ \\
\hline
\end{tabular}

Models 1 and 2 were adjusted for all variables listed in table under each respective model.

*An interaction between year of delivery and all hypertensive disorders of pregnancy was also statistically significant $(P=0.03)$, whereas the interaction between year of delivery and postpartum haemorrhage was not significant $(P=0.18)$. 
Table 5| Temporal trends in rates of pulmonary oedema among all deliveries and among women with and without hypertensive disorders of pregnancy, Canada (excluding Quebec), 2003-10

\begin{tabular}{|c|c|c|c|c|c|c|c|}
\hline \multirow[b]{2}{*}{ Condition } & \multirow{2}{*}{$\begin{array}{l}\text { No of cases in } \\
\text { all years }\end{array}$} & \multicolumn{4}{|c|}{ Rate of pulmonary oedema per 10000 deliveries } & \multirow{2}{*}{$\begin{array}{l}\text { Rate ratio }(95 \% \mathrm{Cl}) 2009-10 \mathrm{v} \\
\qquad 2003-04)\end{array}$} & \multirow[b]{2}{*}{ P for treno } \\
\hline & & 2003-04 & 2005-06 & 2007-08 & $2009-10$ & & \\
\hline All deliveries ( $n=2193425)$ & 515 & 2.7 & 2.5 & 2.0 & 2.3 & 0.86 (0.67 to 1.09$)$ & 0.10 \\
\hline Hypertensive disorders $(n=134490)$ & 306 & 26.3 & 21.9 & 20.3 & 23.0 & $0.87(0.64$ to 1.19$)$ & 0.41 \\
\hline No hypertensive disorders $(n=2058935)$ & 209 & 1.2 & 1.2 & 0.8 & 0.9 & $0.79(0.54$ to 1.15$)$ & 0.06 \\
\hline $\begin{array}{l}\text { Gestational hypertension with significant } \\
\text { proteinuria }(n=24851)\end{array}$ & 174 & 77.0 & 63.9 & 65.6 & 74.1 & $0.96(0.64$ to 1.45$)$ & 0.95 \\
\hline
\end{tabular}




\section{Figure}
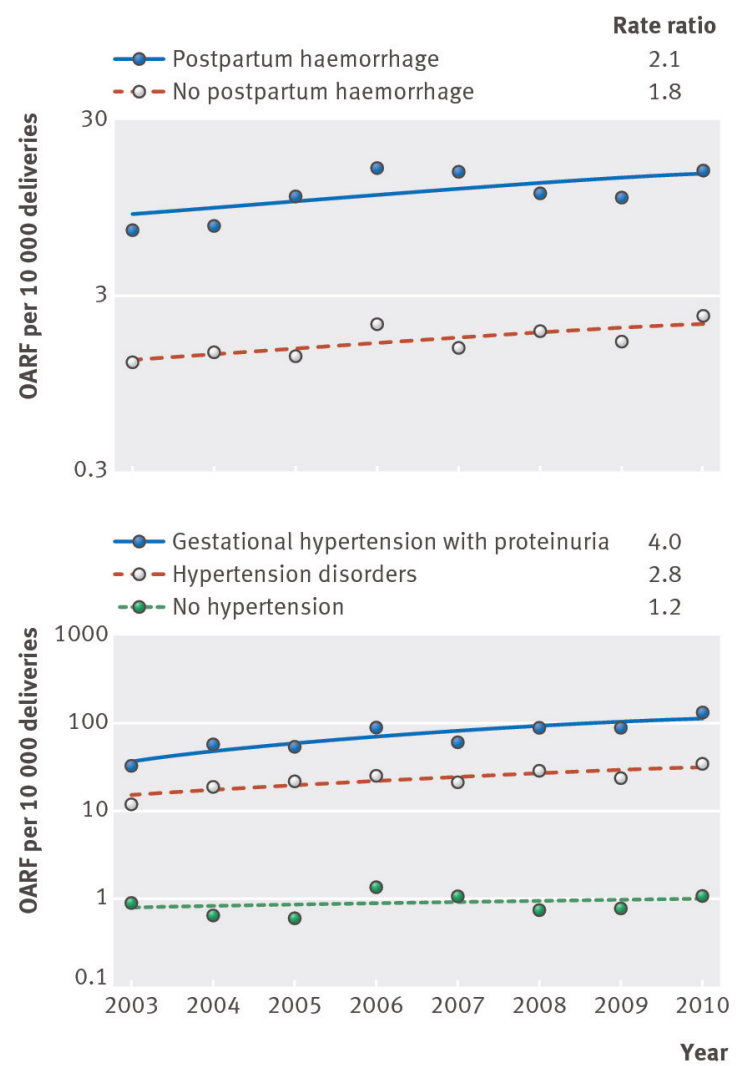

Rates of obstetric acute renal failure (OARF) among deliveries with and without postpartum haemorrhage and among women with gestational hypertension with significant proteinuria, hypertensive disorders of pregnancy, and no hypertension, Canada (excluding Quebec), 2003-10. Rate ratios express changes between 2003 and 2010 and show that temporal patterns in OARF were different among women with and without hypertension (but not among women with and without postpartum haemorrhage) 